\title{
OCCURRENCE OF D-GLYCERYLTAURINE AND AMINO ACID PATTERN IN THE EXTRACTIVES OF A RED ALGA, GYMNOGONGRUS FLABELLIFORMIS
}

\author{
Keiji Iтo* \\ (Received February 18, 1965)
}

In the course of paper chromatographic survey ${ }^{13}$ on the distribution of D-cysteinolic acid in marine algae, a spot positive both for the ninhydrin and $\mathrm{KIO}_{4}$-Nessler reagents ${ }^{2)}$, but clearly differing from those of $\mathrm{D}$-cysteinolic acid or known hydroxyamino acids, was recognized in Gymnogongrus flabelliformis. The substance was isolated and identified as $\mathrm{N}$-[D-2, 3-dihydroxy-n-propyl] taurine (D-glyceryltaurine), the occurrence of which was reported in 1956 by WICKBERG $^{3)}$ in another member of red alga, Gigartina leptorhynchos.

In addition, the extracts of $G$. flabelliformis revealed a peculiar pattern of nitrogen distribution; only $39 \%$ of the extractive nitrogen was accounted for as ammonia and free amino acids, in which arginine, citrulline, glutamic acid and glyceryltaurine predominated. After acid hydrolysis, the figure increased only slightly to $44 \%$, indicating the paucity of peptides in the extracts. At the same time, the composition of amino acids was markedly modified by decrease of arginine and appearance of a considerable quantity of $\gamma$-aminobutyric acid and ornithine.

These observations led the author to study the nitrogenous components of this seaweed more thoroughly and to isolate a new subtance positive for the SAKaGUCHI reagent. The compound gave $\gamma$-aminobutyric acid on hydrolysis and occupied a considerable part of the extractive nitrogen.

In this report, isolation of $\mathrm{D}$-glyceryltaurine and amino acid composition of the extracts before and after hydrolysis are described. The new guanidine compound isolated will be reported in the next paper.

\section{Experimental and Results}

Isolation of $\mathrm{D}$-Glyceryltaurine and Taurine.

Materials of $G$. Alabelliformis were collected at the intertidal region of islands adjacent to Hiroshima in Nov., 1963. The seaweed was washed with fresh water, air-dried and crushed.

One kilogram of the powdered materials (moisture, $10.8 \%$ ) was extracted at $80^{\circ} \mathrm{C}$ for 3 hours with $5 l$. of $75 \%$ ethanol. The cooled mixture was filtered and the residue was treated twice with each $4 l$. portions of the same solvent. The combined ethanolic extracts were concentrated under reduced pressure to about $3 l$. and

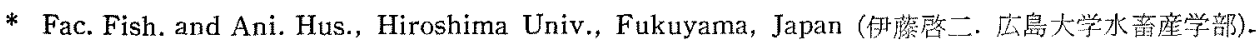


decolorized by treating with ether and charcoal in this order.

The colorless solution thus obtained was passed through a column of Dowex 50 $\mathrm{X}-8\left(50 \times 5.0 \mathrm{~cm}, 20 \sim 50\right.$ mesh, $\mathrm{H}^{+}$form) to remove inorganic salts and amino acids except strongly acidic ones, as in the case of $\mathrm{D}$-cysteinolic acid ${ }^{11}$. The effluent and washings were combined and again passed through a column of Dowex $2 X-8(50 \times 5.0 \mathrm{~cm}$, $20 \sim 50$ mesh, $\mathrm{OH}^{-}$form). The adsorbed fraction was eluted with $4 \%$ acetic acid. After removal of acetic acid by evaporation in vacuum, the residue was dissolved in nearly $10 \mathrm{~m} l$. of water to be put on a long column of Dowex $50 \times-8(140 \times 2.0 \mathrm{~cm}$, $200 \sim 400$ mesh, $\mathrm{H}^{+}$form). The column was eluted with distilled water and the effluent was divided into each $3 \mathrm{~m} l$. portions with a fraction collector. Each tube was checked by paper chromatogrophy using phenol saturated with water as solvent and both developing reagents, $0.2 \%$ ninhydrin and $\mathrm{KIO}_{4}$-Nessler reagent. DGlyceryltaurine began to emerge from the column after approximately $160 \mathrm{ml}$. of effluent had been collected, and was followed by taurine in a slight overlapping.

The fractions contaning taurine $(R f 0.42)$ were combined and concentrated to dryness. The residue was crystallized from aqueous ethanol in prisms, m. p. and mixed m. p., $310^{\circ} \mathrm{C}$. Yield, $0.5 \mathrm{~g}$.

The contents of tube which revealed only one spot of $R f 0.60$ were combined and concentrated to $3 \mathrm{~m} l$. The solution gave colorless thin plates when allowed to stand in an ice-box overnight on addition of $30 \mathrm{ml}$. of $99 \%$ ethanol. The compound was recrystallized from aqueous alcohol to a constant melting point, $162^{\circ} \mathrm{C}$. Yield, 1.8 g. (0.18\%). Molecular weight estimated by the cryoscopic method was 195 200. Anal. Found: C, 30.7; H, 6.57; N, 7.25; S, 15.7. Calcd. for $\mathrm{C}_{5} \mathrm{H}_{18} \mathrm{O}_{5} \mathrm{NS}$ : C, 30.1; $\mathrm{H}, 6.58 ; \mathrm{N}, 7.03 ; \mathrm{S}, 16.1 \% .[\alpha]_{D}^{18.7}=-22.4^{\circ} \quad(C=2.0$ in water $)$.

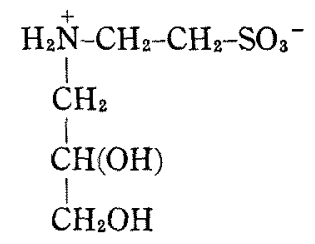

The substance consumed 2.0 moles of periodate and liberated taurine, when $88.3 \mathrm{mg}$ of the crystals was oxidized with periodic acid for 15 hours at room tempera. ture. After the excess periodic acid was decomposed with potassium iodide, free iodine liberated was titrated with sodium thiosulfate. The reaction mixture was then desalued on a column of Dowex 2 X-8. The effluent with $4 \%$ acetic acid was concentrated and kept overnight on addition of alcohol. Taurine was obtained in prisms, m. p. and mixed m. p., $310^{\circ} \mathrm{C}$. Yield, $36.8 \mathrm{mg}$. (66\%).

These results indicate the substance is D-glyceryltaurine (I) and the data agree well with those given by WICKBERG ${ }^{3}$.

Amino acid composition of the ethanolic extractives.

Ten grams of the dried powder was extracted with $75 \%$ ethanol as above and the combined greenish brown extracts were concentrated in vacuum. The aqueous solution was extracted with ether to remove the green pigments, and diluted with 
water to $100 \mathrm{ml}$. The solution was used for estimation of total nitrogen by the micro-KJELDAHL method, $\alpha$-amino nitrogen by the VAN-SLYKE method and amino acids. by the ion-exchange column chromatography"). A part of the solution was hydrolyzed with an equal volume of concentrated hydrochloric acid by boiling under reflux for 15 hours. After excess acid was removed by repeated distillation in vacuum, the residue was dissolved in water to be analyzed for amino acids. The concentration of nitrogen was expressed on the moisture-free basis of materials. The results are summarized in Tables 1 and 2.

As seen in Table 1, nitrogen attributable to amino acids and ammonia corresponds to only $44 \%$ of total nitrogen of ethanolic extracts, even after acid hydrolysis.

Table 1. Distribution of nitrogen in the ethanolic extracts of Gymnogongrus flabelliformis

\begin{tabular}{|c|c|c|c|}
\hline & \multirow{2}{*}{$\begin{array}{c}\text { Cencentration } \\
\mathrm{mg} / \mathrm{g}\end{array}$} & \multicolumn{2}{|c|}{ Distribution } \\
\hline & & $\%$ & $\%$ \\
\hline Air-dried powder. Total N. & 56.14 & 100 & \\
\hline Ethanolic extractives. Total. N. & 12.67 & 22.5 & 100 \\
\hline $\begin{array}{c}\alpha-\text { Amino } \mathrm{N} \\
\left(\mathrm{V}_{\text {AN-SLYKE) }}\right)\end{array}\left\{\begin{array}{l}\text { before hydrolysis } \\
\text { after hydrolysis }\end{array}\right.$ & $\begin{array}{l}2.41 \\
3.85\end{array}$ & & $\begin{array}{l}19.0 \\
30.4\end{array}$ \\
\hline $\begin{array}{l}\text { Amino acid- } \\
\text { and } \mathrm{NH}_{3}-\mathrm{N}^{*}\left\{\begin{array}{l}\text { before hydrolysis } \\
\text { after hydrolysis }\end{array}\right.\end{array}$ & $\begin{array}{l}4.90 \\
5.59\end{array}$ & & $\begin{array}{l}38.7 \\
44.1\end{array}$ \\
\hline
\end{tabular}

* Calculated from analytical data shown in Table 2.

In the elution curve from the long column of Dowex 50 resin, a few peaks of unidentified compounds appeared before the aspartic acid and they were not affected by hydrolysis. These compounds, however, seem to be insignificant in quantity. The taurine peak reduced nearly to half on acid hydrolysis. As taurine is considered to be stable in the hydrolysis conditions adopted, this may show the coexistence of unknown compounds which are decomposed by hydrolysis and entirely overlap the taurine peak in elution. Therefore, this peak is expressed as taurine and unknown compounds in Table 2 and tentatively calculated as taurine. ${ }^{-}$-Glyceryltaurine also overlaps taurine, but the color yield with ninhydrin is only 0.05 in leucine equivalent and may have little connection with this calculation. The value of $\mathrm{D}$-glyceryltaurine given in Table 2 is based on the yield in isolation. Thus, some ambiguity still remains in the composition of acidic amino acids and this may cause some errors in calculation of nitrogen recovery.

The composition of free amino acids is characterized by the predominance of arginine, citrulline, glyceryltaurine and glutamic acid and these four amino acids account for more than $89 \%$ of free amino acid nitrogen. On hydrolysis, nearly half of arginine disappears and both amino acids, $\gamma$-aminobutyric acid and ornithine newly appear in a considerable quantity. The other amino acids, such as alanine, aspartic acid, glycine, phenylalanine, serine and threonine, show the increase more or less, probably due to hydrolysis of peptides. 
Table 2. Composition of amino acids in the ethanolic extracts of G. flabelliformis (mg.\%)

\begin{tabular}{|c|c|c|c|c|}
\hline \multirow{2}{*}{ Amino acids } & \multicolumn{2}{|c|}{ Before hydrolysis } & \multicolumn{2}{|c|}{ After hydrolysis } \\
\hline & Concn. & $\mathrm{N}$ & Concn. & $\mathrm{N}$ \\
\hline Alanine & 55.0 & 8.64 & 67.4 & 10.6 \\
\hline$\gamma$-Aminobutyric acid & 0 & 0 & 367.0 & 49.9 \\
\hline Arginine (?) & 710.0 & 228,0 & 305.0 & 97.7 \\
\hline Aspartic acid & 27.8 & 2.93 & 49.7 & 5.23 \\
\hline Citrulline & 268.0 & 64.2 & 91.5 & 22.0 \\
\hline Glutamic acid & 212.0 & 20.2 & 272.0 & 25.9 \\
\hline Glycine & 14.5 & 2.70 & 66.5 & 12.4 \\
\hline Isoleucine & trace & - & trace & - \\
\hline Leucine & trace & - & trace & - \\
\hline Ornithine & 0 & 0 & 441.0 & 94.5 \\
\hline Phenylalanine & 39.4 & 3.34 & 50.7 & 4.30 \\
\hline Serine & trace & - & 90.7 & 12.1 \\
\hline Threonine & trace & 一 & 31.6 & 3.72 \\
\hline Valine & trace & - & trace & - \\
\hline $\begin{array}{l}\text { Taurine and } \\
\text { unknown compounds }\end{array}$ & 204.0 & 22.9 & 99.0 & 11.1 \\
\hline $\mathrm{NH}_{3}-\mathrm{N}$ & & 122.1 & & 195.0 \\
\hline Glyceryltaurine & 203.0 & 14.3 & 203.0 & 14.3 \\
\hline Total & & 489.3 & & 558.8 \\
\hline
\end{tabular}

\section{Discussion}

The occurrence of D-glyceryltaurine in ethanolic extracts of $G$. flabelliformis was established. Since WICKBERG found this substance in Gigartina leptorhynchos for the first time, it has not been detected in a large number of seaweeds investigated in several laboratories ${ }^{5 \sim 11}$. Reinvestigation of thirteen species of marine algae, which had been examined on cysteinolic acid in the previous paper ${ }^{1)}$, resulted in detecting it only in $G$. flabelliformis. This may show the very limited distribution of the amino acid in marine algae.

Besides the characteristic pattern of free amino acids, a marked change of some amino acids during acid hydrolysis may be worthy of special mention. The possibility of ornithine formation from citrulline ${ }^{8 \prime}$ or $\operatorname{arginine}^{12)}$ in hydrolysis has been described. The test to see the stability of both amino acids during hydrolysis under the conditions adopted in the present study cleary showed the loss of $50 \sim 70 \%$ of citrulline. Arginine, on the other hand, was quite intact throughout the procedure. These observations may suggest that a part of ornithine formed is attributable to the destruction of citrulline and the considerable loss of argnine observed may be due to the coexistence of some unknown factors in the extracts, which enhance the 
degradation of arginine or overlap the arginine peak as was observed on the taurine peak. Such degradation of arginine, if present, might be related with the formation of ornithine to some extent. These are, however, problems to be solved in future.

Differing from ornithine, the origin of $\gamma$-aminobutyric acid was satisfactorily explained by isolation of a new guanidine compound, which will be reported in the next paper.

\section{Summary}

Occurrence of D-glyceryltaurine in the ethanolic extracts of a red alga, Gymnogongrus flabelliformis has been established.

Only $39 \%$ of the extractive nitrogen was accounted for as ammonia and free amino acids, in which arginine, citrulline, glutamic acid and glyceryltaurine predominated. After acid hydrolysis, the figure increased only to $44 \%$, indicating the paucity of peptides and the amino acid pattern was markedly changed by the formation of $r$-aminobutyric acid and ornithine, in place of the considerable loss of arginine and citrulline.

\section{Acknowledgement}

The author wishes to express here his thanks to Prof. Y. Hashmoto, Tokyo University and Prof. F. Matsumoto, Hiroshima University for their suggestion and advice he received in the cource of this work.

\section{References}

1) Iто, K: This Bull., 29, 771 (1963).

2) Block, R. J., Durrum, E. L. and Zweig, G.: A manual of paper chromatography and paper electrophoresis, p. 97, Academic Press. Inc., New York (1957).

3) Wickberg, B.: Acta Chem. Scand., 10, 1097 (1956).

4) Moore, S., and Stein, W. H.: J. Biol. Chem., 192, 663 (1951).

5) Takagi, M., and KuriYama, M.: Bull. Fac. Fish., Hokkaido Univ., 10, 72 (1959).

6) Young, E. G. and Smith, D. G.: J. Biol. Chem., 233, 406 (1958).

7) Kimura, Y. et al.: Sōgō Kaiyo Kagaku, 2, 215 (1960), 3, 103 (1961).

8) Lewis, E. J. and Gonzalves, E. A.: Ann. of Botany, 26, 301, 317 (1962).

9) KuriYama, M.: This Bull., 27, 689 (1961).

10) TaKagi, M. and Nakamura, S.: ibid., 30, 279 (1964).

11) Takagi, M., Ishihara, S., Nishide, H., Yamada, Y. and Murayama, H.: ibid., 30, 284 (1964).

12) Meister, A.: Biochemistry of Amino Acids, p. 37, Academic Press. Inc., New York (1957). 